\title{
POSSIBLE ETIOLOGICAL FACTORS OF SELF- MEDICATION - A PRACTICAL STUDY ON DIFFERENT GROUPS
}

\section{Mohamed Moussa ${ }^{(1)}$; Salah Mostafa ${ }^{(2)}$ and Mostafa M. Hegazy ${ }^{(3)}$}

1) Post graduate student at Faculty of Graduate Studies and Environmental Research, Ain Shams University 2) Faculty of Postgraduate Childhood Studies, Ain-Shams University 3) Faculty of Pharmacy, Al-Azhar University

\section{ABSTRACT}

Background: Self-Medication is an increasingly frequent worldwide health problem especially in developing countries like Egypt. Some studies suggest that there is a relationship with socioeconomic (SES) and environmental factors.

Objective: This study aimed to describe the prevalence, pattern, possible etiological factors and reasons of self- medication among adults attending two private pharmacies from different regions (slum and urban) with different socioeconomic and environmental status in Cairo, Egypt.

Methodology: This is a cross-sectional study carried out from September to December2020; a random sample of 150 adults completed a predesigned selfadministered interview questionnaire on self-medication practices.

Results: a majority of participants practiced self-medication with a prevalence rate $(73.4 \%)$. Common cold, headache, cough and gastrointestinal diseases were the most common illnesses among adults opting for selfmedication (SM) and they tended to select SM if the illness was minor. Residence and family expenses were the independent determinant variables in socioeconomic status significantly affecting the practice of self-medication.

Conclusion: the prevalence of self-medication with medicines is high among adults in urban and slum areas of Cairo, Egypt that needs intervention.

Recommendation: further studies need to be done in order to extend this study outside the capital city; Cairo to include other cities, slum and rural areas in Egypt.

Keywords: self-medication, socioeconomic status, environmental.

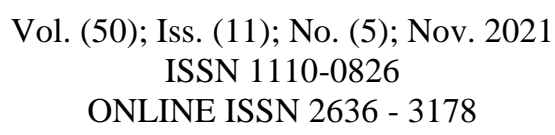


Journal of Environmental Sciences (JES)

Faculty of Graduate Studies and Environmental Research, Ain Shams University

Moussa et al.

\section{INTRODUCTION}

Self-Medication (SM) is usually defined as intake of any type of drugs for treating oneself without professional supervision to relieve an illness or a condition (Bennadi, 2013). The public health importance of SM has increased since the late 1980s. When more drugs are switched to be sold Over The Counter (OTC) without prescription. Many of these drugs have potentially serious side effects and need to be used with care (WHO, 2000). Indeed, SM with OTC medications is a worldwide public health problem in both developed and developing countries but more experienced among individuals in many developing countries including Egypt where many drugs are dispensed OTC without medical direction. The possible etiological factors and reasons for using SM are poorly understood (El-Nimr et al., 2015).

SM patterns vary among different populations from country to country and are influenced by various features such as age, gender, income, self-care orientation, educational level, medical knowledge, previous experience, satisfaction and seriousness of illnesses (Susheela, et al., 2018). The prevalence of SM is more in low-to middle income countries and is more common in countries where prescription legislation is not strong enough (Bennadi, 2013). Egypt is no exception in this regard (Abdelaziz et al., 2019).

In Egypt, like most developing countries such as Malaysia and Jordan, studies have revealed an increase in trends of SM, particularly among patients (adults) of general population attending private pharmacies, where most 
Journal of Environmental Sciences (JES)

Faculty of Graduate Studies and Environmental Research, Ain Shams University

Moussa et al.

illnesses are treated by SM (El-Nimr et al, 2015; Hassali et al, 2011; Yousef et al, 2008).

Despite the importance of the problem of SM among patients (adults) attending private pharmacies in Egypt, a limited number of drug utilization studies have been conducted. Two studies are carried out in Alexandria (Sallam et al, 2009; El-Nimr et al, 2015). Another study carried out among adults in Minia, Egypt (Ghazawy et al, 2017).

Therefore, the main objectives of this study are to determine: The pattern and prevalence of SM practices among patients (adults) attending to private pharmacies in two different regions with different socioeconomic and environmental statuses in Cairo, Egypt, the most probable determinants, types of medications used, sources of advice and possible etiological factors (reasons) for SM.

\section{METHODOLOGY}

Patients and Methods: The study design is across-sectional and followed WHO guidelines for investigation of therapeutic practice (WHO guidelines, 1993). Accordingly, this study is carried out using self-administered questionnaires among adults (patients) attending two private pharmacies in two different regions in Cairo, Egypt, to participate voluntary customers four days per week, for four months from September to December, 2020 and are selected randomly. 
They contain two different groups:

Group I: Urban customers (110/73.3\%) attending private pharmacy in ElRehab city, Cairo, Egypt with high SES and environmental status.

Group II: Slum customers (40/26.7\%), attending private pharmacy with low SES and environmental status and live at Ezbit-Elhaggana, slum region in Cairo, Egypt.

Sampling: The required sample size is determined by Epi Info program on mobile based on Epi Info Program, CDC, Atlanta, Georgia, USA, 2020. The program shows the needed sample is 150 .

Inclusion Criteria: The total number of (150) adult participants are included in the study.

Exclusion Criteria: Persons who are unable to answer the questions or give incomplete response due to some barriers are excluded from the study.

Ethical Consideration: This study is approved by the ethics Committee of the Institute of Environmental Studies and Research, Ain-Shams University.

Prior to data collection, informed verbal consents are obtained from all participants included in the study, after supplying comprehensive information about the nature and the objectives of the study.

Data Collections: A predesigned self-administered questionnaire is prepared initially in English from previous studies (Helal and Abou-ElWafa, 2017; Ghazawy et al., 2017; ElEzz and Ez Elarab, 2011) and developed by the investigator then translated into Arabic and used to collect the following data on SM practices. The questionnaire consists of three sections; the first section 446 
Journal of Environmental Sciences (JES)

Faculty of Graduate Studies and Environmental Research, Ain Shams University

Moussa et al.

includes the SES of customers for SM e.g. age, sex, residence, marital status, occupation, insurance state, income and level of education.

The second section includes health related questions for customers of SM e.g. current health status, which include the medical history of the interviewees (chronic diseases; diabetes, hypertension and others), care about health and drugs stored at home (remembered only if present).

The third section dealt with SM practices that include conditions in which the patients (adults) believe that SM is convenient, drugs used, possible etiological factors (reasons) for SM, sources of advice, advantages and disadvantages of SM and knowledge about drugs used for SM as well as question about the role of pharmacist in educating his customers about the proper use of medications which intended for SM.

Finally, this part also contains, recent attitude towards SM and include questions about; reading the package leaflet of SM drugs by customers, trust of customers with the correct package leaflet of most medicinal products and a question about encouragement of family and friends to self-medicate.

\section{Statistical Analysis:}

- The data was collected, cleaned, filtered, coded and entered into the Microsoft Office, Excel Program (2010).

- SPSS statistics (Statistical Package for Social Sciences; version 12, 2004 program) was used for data entry and analysis.

- Data was analyzed and presented using tables and graphs. Descriptive data, frequency and percentage (mean \pm SD) for analyzed statistics. A 
probability value ( $p$-value) less than or equal to $(p \leq 0.05)$ was considered significant. A $\mathrm{p} \leq 0.01$ was considered highly significant.

\section{RESULTS}

This study included 150 adults whose age ranged from 18-67 years with a mean (31.3 \pm 8.2$)$. There were $100(66.7 \%)$ males and 50 (33.3\%) females.Participants who had practiced some sort of SM during the past month were $110(73.4 \%)$.

Socioeconomic status of the participants (adults): Most of the residents $110(73.3 \%)$ were from urban areas and 40 were (26.7\%) from slum areas attending two private pharmacies from two different regions with different socioeconomic status in Cairo, Egypt. The majority 79 (52.3\%) were married, $129(86 \%)$ of the participants have professional job, and $123(82 \%)$ were insured. As regard family expenses per week 81 (54\%) of participants showed average (2000-4000) family expenses. As regard education, 132 (88\%) of adults have academic education, while 123 (82\%) were healthy, 117 (78\%) showed care about their health, and 112 (80\%) of participants have drugs stored at home pharmacy. As regard frequency of age of the study group 95 $(63.3 \%)$ of adults are between (18-30 years). (table 1$)$ 
Journal of Environmental Sciences (JES)

Faculty of Graduate Studies and Environmental Research, Ain Shams University

Moussa et al.

Table (1): socioeconomic status of the participants

\begin{tabular}{|c|c|c|c|}
\hline Categories & Features & No., mean, SD & $\%$ \\
\hline \multirow{3}{*}{ 1. Practice $S M, p=0.002$} & Yes & 110 & 73.4 \\
\hline & No & 40 & 26.6 \\
\hline & Total & 150 & 100.0 \\
\hline 2. Age & Number $=150$ & \multicolumn{2}{|c|}{ Mean $31.3+/-8.2$} \\
\hline \multirow{3}{*}{ 3. Sex } & Male & 100 & 66.7 \\
\hline & Female & 50 & 33.3 \\
\hline & Total & 150 & 100.0 \\
\hline \multirow{3}{*}{ 4. Residence, $p=0.001$} & Urban & 110 & 73.3 \\
\hline & Slum & 40 & 26.7 \\
\hline & Total & 150 & 100.0 \\
\hline \multirow{5}{*}{ 5. Marital status } & Married & 79 & 52.3 \\
\hline & Divorced & 2 & 1.3 \\
\hline & Widow & 1 & 0.7 \\
\hline & Single & 68 & 45.3 \\
\hline & Total & 150 & 100.0 \\
\hline \multirow{5}{*}{ 6. Work } & Professional & 129 & 86 \\
\hline & Technical & 10 & 6.7 \\
\hline & Handiwork & 1 & 0.7 \\
\hline & Doesn't work & 10 & 6.7 \\
\hline & Total & 150 & 100.0 \\
\hline \multirow{3}{*}{ 7. Health Insurance } & Insured & 123 & 82.0 \\
\hline & Non insured & 27 & 18.0 \\
\hline & Total & 150 & 100.0 \\
\hline \multirow{4}{*}{$\begin{array}{l}\text { 8. Family expense per } \\
\text { week } \mathrm{P}=0.005\end{array}$} & More than $4000 \mathrm{LE}$ & 39 & 26.0 \\
\hline & 2000-4000 LE & 81 & 54.0 \\
\hline & Less than $2000 \mathrm{LE}$ & 30 & 20.0 \\
\hline & Total & 150 & 100.0 \\
\hline \multirow{5}{*}{ 9. Education } & Academic qualification & 132 & 88.0 \\
\hline & Average qualification & 11 & 7.3 \\
\hline & Elementary education & 6 & 4.0 \\
\hline & Illiterate & 1 & 0.7 \\
\hline & Total & 150 & 100.0 \\
\hline
\end{tabular}

Vol. (50); Iss. (11); No. (5); Nov. 2021

ISSN $1110-0826$

ONLINE ISSN 2636 - 3178 
Journal of Environmental Sciences (JES)

Faculty of Graduate Studies and Environmental Research, Ain Shams University

Moussa et al.

\begin{tabular}{|c|c|c|c|}
\hline Categories & Features & No., mean, SD & \% \\
\hline \hline \multirow{4}{*}{ 10.Health status } & Healthy & 123 & 82.0 \\
\cline { 2 - 4 } & Diabetes & 12 & 8.0 \\
\cline { 2 - 4 } & other diseases & 8 & 5.3 \\
\cline { 2 - 4 } & Hypertension & 6 & 4.0 \\
\cline { 2 - 4 } & Diabetes \& hypertension & 1 & 0.7 \\
\cline { 2 - 4 } & Total & 150 & 100.0 \\
\hline \multirow{3}{*}{ 11.Care about health } & Yes & 117 & 78 \\
\cline { 2 - 4 } & do not care & 150 & 100.0 \\
\cline { 2 - 4 } 12.Drugs stored at home \\
pharmacy
\end{tabular}

In the present study, regarding socioeconomic factors such as age, residence, family expenses per week, gender, marital status, work, medical insurance, education, current health status, care about health and drugs stored at home.

No statistically significantly difference were observed between persons who practiced SM and those who were not except for the residence $\left(\mathrm{F}_{1} ; 10.1\right.$, $\mathrm{p}=0.002$ and $\left.\mathrm{F}_{2} ; 11.2 \mathrm{p}=0.001\right)$, and family expenses $(\mathrm{F} ; 5.51 \mathrm{p}=0.005)$, respectively. (Tables $6 \& 7$ )

Regarding drugs stored at home pharmacy constituted $80 \%$ of selfmedicated participants. The commonest source of information about the drugs used for SM was the pharmacist (72\%). (Tables $1 \& 2$ ) 
Moussa et al.

Table (2): Sources of medication and main information on Self-Medication (SM), from 150 of participants

\begin{tabular}{|c|c|c|}
\hline Sources of information on self-medication & No. & $\mathbf{\%}$ \\
\hline Pharmacist/ pharmacy clerk & 79 & 72 \\
\hline Old prescription & 59 & 39.3 \\
\hline My decision of participants & 56 & 37.3 \\
\hline Others (Internet and Advertisements) & 32 & 21.3 \\
\hline Books \& magazine & 31 & 20.7 \\
\hline Media and Social media sites & 31 & 20.7 \\
\hline Neighbors \& family & 30 & 20 \\
\hline Friends & 25 & 16.7 \\
\hline
\end{tabular}

Followed by previous experience or knowledge from previous prescription (39.3\%), after that SM upon my decision of participants (37.3\%) then $21.3 \%$ for internet and advertisement, books and magazines (20.7\%) also mass media $20.7 \%$, family and neighbors $20 \%$, while relatives and friends were the least source of information about the drugs and questions related to SM (16.7\%). Table (2)

The commonest reason for SM was "there is no need to visit the doctor in minor illnesses" (57.3\%). 52\% showed that "confidence in the pharmacist'. this was followed by "' cost of consultation with the doctor" (50.7\%). About $46.7 \%$ indicated 'time and money saving', $44.7 \%$ reported 'easy accessibility of medicines from pharmacy without prescription"' and $42.7 \%$ indicated 'the availability of insurance service'" followed by (40\%) reported 'fast relief'; $28 \%$ indicated 'chance to have experience', $26 \%$ for "'unavailability of health service', and the least reason was '"absence of trust in health services"' (22.7\%). Table (3) 
Moussa et al.

Table (3): Main Reasons for SM, from 150 of participants

\begin{tabular}{|c|c|c|}
\hline Reasons for using self-medication (advantages) & No. & \% \\
\hline \hline No need to visit the doctor for a minor disease & 86 & 57.3 \\
\hline Confidence in the pharmacist & 78 & 52.0 \\
\hline Cost of consultations with the doctor & 76 & 50.7 \\
\hline Time and money saving & 70 & 46.7 \\
\hline Availability of drugs from pharmacy without prescription & 67 & 44.7 \\
\hline Availability of medical insurance & 64 & 42.7 \\
\hline Fast relief & 60 & 40.0 \\
\hline The doctor will prescribe me the same drug & 55 & 36.7 \\
\hline Chance to have experience & 42 & 28.0 \\
\hline Unavailability of health service & 39 & 26.0 \\
\hline Absence of trust in health services & 34 & 22.7 \\
\hline
\end{tabular}

The most common perceived illnesses for SM were common cold (72\%), headache $(70 \%)$, cough $(50.7 \%)$, sore throat $(45.3 \%)$, and toothache $(38 \%)$, regarding GIT problems such as diarrhea (43.3\%), vomiting (28.7\%) and liver problems (12.7\%), while participants suffering from fever (24\%).Table (4)

The most frequently consumed drugs in the current study were common cold preparations (72\%), followed by analgesics for headache (70\%), and cough sedatives $(50.7 \%)$. Table (4) 
Faculty of Graduate Studies and Environmental Research, Ain Shams University

Moussa et al.

Table (4): possible etiological factors for Self-Medication (SM), from 150 of participants

\begin{tabular}{|c|c|c|}
\hline Most common perceived illnesses for self-medication & No. & $\mathbf{\%}$ \\
\hline Common cold & 108 & 72.0 \\
\hline Headache & 105 & 70.0 \\
\hline Cough & 76 & 50.7 \\
\hline Sore throat & 68 & 45.3 \\
\hline toothache & 57 & 38.0 \\
\hline Others mainly gastrointestinal tract & 50 & 33.3 \\
\hline Abdominal pain & 65 & 43.3 \\
\hline Diarrhea & 58 & 38.7 \\
\hline Constipation & 76 & 50.7 \\
\hline Heart burn & 43 & 28.7 \\
\hline Vomiting & 54 & 36.0 \\
\hline Indigestion & 19 & 12.7 \\
\hline Liver problems & \multicolumn{2}{|c|}{} \\
\hline Chronic diseases & 33 & 22.0 \\
\hline Diabetes & 23 & 15.3 \\
\hline Atherosclerosis & 31 & 20.7 \\
\hline Hypertension & 66 & 44.0 \\
\hline Others & 36 & 24.0 \\
\hline Fever & \multicolumn{1}{|c|}{} \\
\hline Self-medicated drugs solved the symptom &
\end{tabular}

About $44 \%$ of the self-medicated drugs solved the symptoms among adults in Cairo, Egypt. Less frequently reported drugs used in SM included antihypertensives (20.7\%) and drugs for diabetes (22\%). Table (4)

As regard the modern trend about SM, 52\% reported reading the drug leaflet about SM, while 54.7\% having the trust about drug leaflet and most of the medicinal products, and $28.7 \%$ for encouragement of family and friends for using SM. Table(5) 
Table (5): Main Reasons for not Using SM and Modern Trend toward SM, from 150 of participants

\begin{tabular}{|c|c|c|}
\hline Reasons for not using self-medication (disadvantages) & No. & $\%$ \\
\hline Fear of adverse effects & 78 & 52.0 \\
\hline Lack of knowledge \& experience & 76 & 50.7 \\
\hline Lack of confidence & 52 & 34.7 \\
\hline it is injurious to health & 36 & 24.0 \\
\hline Prior bad experience with self-medication & 39 & 26.0 \\
\hline Recent attitude towards self-medication & 78 & 52.0 \\
\hline Reading the package leaflet of self-medicated drugs & 82 & 54.7 \\
\hline Believe what they read in the leaflet of medicinal products & 43 & 28.7 \\
\hline I encourage friends and family to self-medicate
\end{tabular}

Regarding for not using SM the commonest cause was 'fear of adverse effects of drugs", (52\%), followed by "'lack of knowledge and experience", (50.7\%), lack of trust (34.7\%) then 'SM is injurious to health', $(24 \%)$ and the last one "previous bad experience with SM " (26\%). Table (5)

Table (6): the relation of residence of patients and drugs related to selfmedication, moreover, "ask questions about self-medication"

\begin{tabular}{|c|c|c|c|c|}
\hline Variable & Sample & N & Mean & SD \\
\hline \hline \multirow{2}{*}{$\begin{array}{c}\text { 1. Diseases and drugs related to self- } \\
\text { medication }\left(\mathrm{F}_{1}\right)\end{array}$} & Slum & 40 & 79.8 & 17.4 \\
\cline { 2 - 5 } & Urban & 110 & 71.0 & 13.8 \\
\cline { 2 - 5 } & Total & 150 & 73.4 & 15.3 \\
\hline \multirow{2}{*}{ 2.Ask customers about self-medication $\left(\mathrm{F}_{2}\right)$} & Slum & 40 & 66.7 & 10.4 \\
\cline { 2 - 5 } & Urban & 110 & 61.2 & 8.5 \\
\cline { 2 - 5 } & Total & 150 & 62.6 & 9.3 \\
\hline
\end{tabular}

$\mathrm{F}_{1} ; 10.1, \mathrm{p}=0.002$

$\mathrm{F}_{2} ; 11.2 \mathrm{p}=0.001$ 
Moussa et al.

This table shows the mean scores of diseases drug related selfmedication, slum 79.8 versus urban 71.0 , this difference is statistically significant, $\mathrm{F}=10.1, \mathrm{P}=0.002$. Also the mean scores of ask customers about self-medication, slum 66.7 versus urban 61.2.

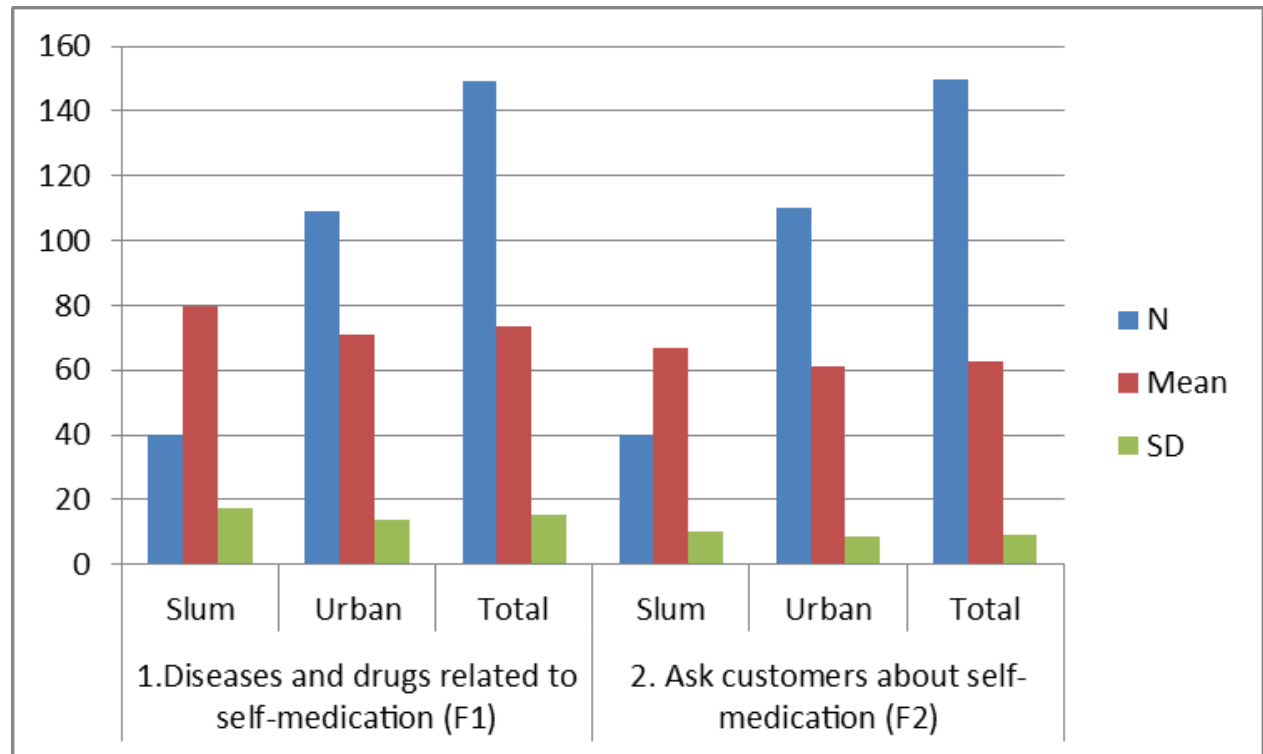

Figure (1): the relation of residence of patients and drugs related to selfmedication, moreover, "ask customers about self-medication"

Table (7): the relation of family expenses with " ask customers about selfmedication",

\begin{tabular}{|c|c|c|c|c|}
\hline Variable & Family expense (EGP) & N & Mean & SD \\
\hline \hline \multirow{3}{*}{$\begin{array}{c}\text { Ask customers about self- } \\
\text { medication (F) }\end{array}$} & Low < 2000 & 30 & 66.5 & 10.8 \\
\cline { 2 - 5 } & Av 2000-4000 & 81 & 60.5 & 8.4 \\
\cline { 2 - 5 } & High > 4000 & 39 & 64.1 & 5.9 \\
\cline { 2 - 5 } & Total & 150 & 62.6 & 9.3 \\
\hline
\end{tabular}

$\mathrm{F} ; 5.51 \mathrm{p}=0.005$ 
This table shows the mean scores of Ask customers about selfmedication, Low < 200066.5 versus High >4000 64.1, these differences is statistically significant, $\mathrm{F}=5.51, \mathrm{P}=0.005$.

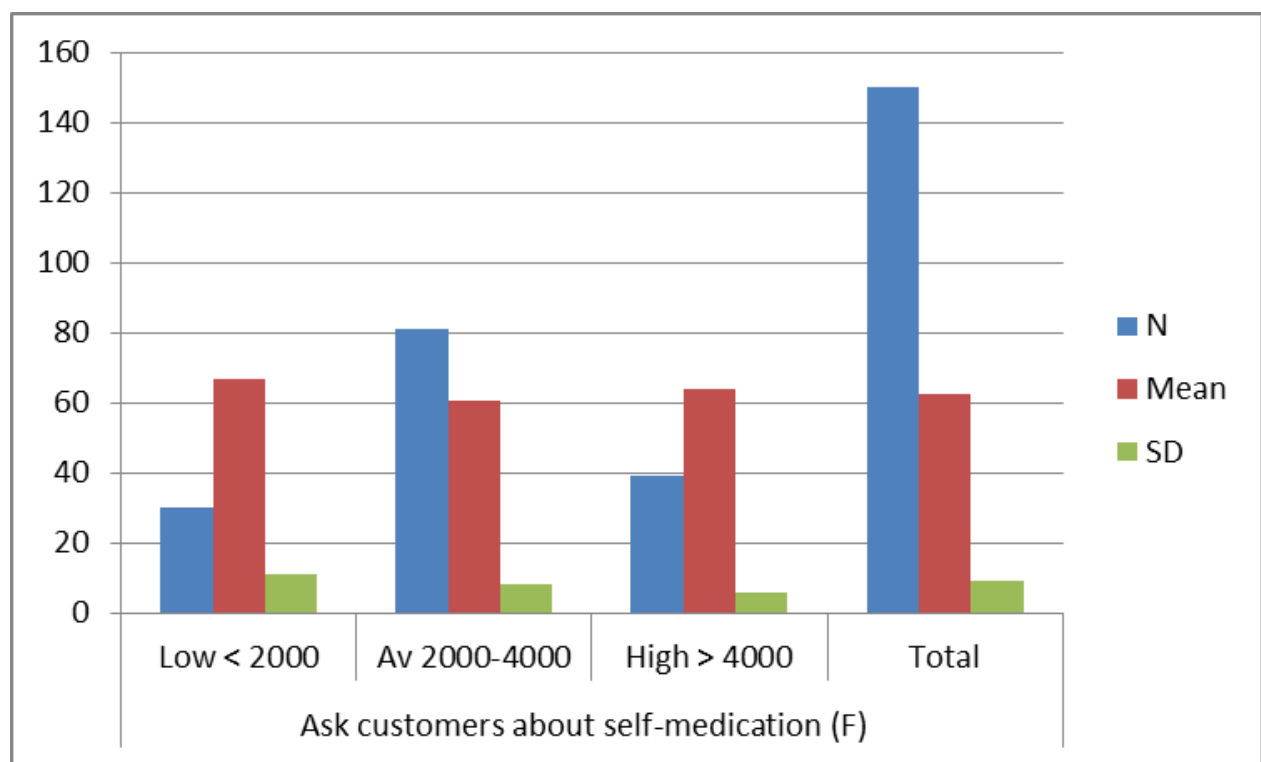

Figure (2): the relation of family expenses with "ask customers about selfmedication",

\section{DISCUSSION}

Access to medicine without prescription confirmed SM practice that is a global challenge. Like several studies on SM have described the pattern of utilization of drugs in developed and developing countries, WHO, 2000.In Egypt the utilization of specific drugs, notably common cold preparations and analgesics has been studied, El-Nimr et al, 2015. 
Journal of Environmental Sciences (JES)

Faculty of Graduate Studies and Environmental Research, Ain Shams University

Moussa et al.

In the current study within a sample of 150 adults attending two private pharmacies from two different regions (urban and slum) with different socioeconomic status in Cairo, Egypt, whose ages ranged from 18-67 years with a mean $(31.3 \pm 8.2)$. There were $100(66.7 \%)$ males and $50(33.3 \%)$ females.

Also, $(18 \%)$ of the studied groups mentioned having a chronic health problems / disease (Diabetes, hypertension and others), it appears that SM was not so much used for chronic health conditions as for acute minor common conditions. The most common perceived illnesses for SM were common cold $(72 \%)$, headache $(70 \%)$, cough $(50.7 \%)$, sore throat $(45.3 \%)$, and toothache (38\%), regarding GIT problems such as diarrhea (43.3\%), vomiting (28.7\%) and liver problems (12.7\%), while participants suffering from fever $(24 \%)$.

Our results were in consistent with Ghazawy et al., 2017 and El-Nimr et al, 2015 who reported that seven out of every eight adults included in his study had practiced SM at least once during the previous year. The most frequently consumed drugs in the current study were common cold preparations (72\%), followed by analgesics for headache (70\%), and cough sedatives (50.7\%).Less frequently reported drugs used in SM included antihyertensives $(20.7 \%)$ and drugs for diabetes (22\%). The same findings were in accordance with El-Nimr et al, 2015.

Prevalence of SM: The prevalence of SM in this study was found $73.4 \%$ among adults in Cairo, Egypt. Similar findings have been reported in other 
Journal of Environmental Sciences (JES)

Faculty of Graduate Studies and Environmental Research, Ain Shams University

Moussa et al.

studies such as SM among adults was (73\%) in Minia, Egypt (Ghazawy et al, 2017) $73.6 \%$ in Brazil (Pons et al, 2017);72.4\% among attendants to a family center in Al-Sadat City, Menoufia Governorate, Egypt (Farahat et al, 2016). Our estimates are lower than the figures reported from previous studies conducted in Alexandria, it was found that $86.4 \%$ and $81.1 \%$ of the participants practiced SM, respectively (El-Nimr et al, 2015;Sallam et al, 2009). 87\% in Palestine (Al-Ramahi, 2013); 95\% in Karachi (Safila et al, 2014); 80\% among general public in Taif, KSA (Abdallah, 2014).

Similarly, 93.7\% in pharmacy outlets of Asmara, Eretria (Tesfamariam et al, 2019); and 83.3\% for SM practices in Khartoum state, Sudan (Awad et al, 2006). The major influential reason behind the higher propensity of SM might be unregulated easy availability of all categories of medicines without prescription (Tesfamariam et al, 2019).

On the contrary, our findings were still higher than other studies as in Minia, Upper Egypt where antibiotic SM practice among adults was (63\%) (Abdel Aziz et al, 2019); 62.9\% among university students in the city of Mansoura, Egypt (Helal and Abou-ElWafa, 2017); 61\% in Cairo pharmacies (Sabry et al, 2014); 55.2\% among medical students, Ain Shams University (El Ezz and Ez-Elarab, 2011); 21.1\% in Cairo hospitals (Sallam et al, 2009).

Prevalence of SM in our study was also still higher than others in Amman, Jordan (42.5\%) (Yousef et al, 2008); 62\% was among adults attending community pharmacies in Malaysia (Hassali et al, 2011); and 27\% was in a national survey in China (Yuefeng et al, 2012). 
Journal of Environmental Sciences (JES)

Faculty of Graduate Studies and Environmental Research, Ain Shams University

Moussa et al.

The relation of socioeconomic factors of diseases and drugs related to SM, moreover, " ask questions about SM":

In the current study, the relation of residence of patients and drugs related to $\mathrm{SM}$, moreover, "ask questions about $\mathrm{SM}$ " in slum $(\mathrm{N}=40)$ was $79.8 \%$ versus urban $(\mathrm{N}=110)$ was $71 \%$, it was statistically significantly different $\left(\mathrm{F}_{1}=10.1, \mathrm{p}=0.002\right)$. Also, the mean scores of questions about SM in slum area was $66.7 \%$ versus urban area was $61.2 \%$ and it was statistically significantly different $\left(\mathrm{F}_{2}=11.2, \mathrm{p}=0.001\right)$. However, the relation of family expenses with diseases and drugs related to SM, moreover, "ask questions about SM" showed that the mean scores of ask questions about SM in low income (slum) population < 2000 was $66.5 \%$ versus high income (urban) population $>4000$ was $64.1 \%$ and it was statistically significantly different $(\mathrm{F}=5.51, \quad \mathrm{p}=0.005)$.

As WHO noted SM provides a cheap alternative to people who cannot afford to pay medical practitioners. Thus, SM is often the first option response to illness among people of the low-income class (WHO, 2000). This is in consistent with the findings of the present study and other study has identified income as a contributing factor (Yuefeng et al, 2012). In the light of our results for income in relation to SM, a similar study from Nepal reported that the poor socioeconomic status, the high cost of medicines, lack of availability of physicians in rural areas and difficulties in accessing modern healthcare services were the major factors for SM (Shankar et al, 2002). 
Journal of Environmental Sciences (JES)

Faculty of Graduate Studies and Environmental Research, Ain Shams University

Moussa et al.

The association between self- assessment of health and use of nonprescribed medication appears in a study conducted in Amman, Jordan, which revealed that Jordanians, who had health insurance plans and people living in high income urban residential area (West Amman), were the least to justify SM by lowering the overall healthcare cost (Yousef et al, 2008). This is in agreement with our findings in this study. Similarly, respondents with higher income appeared less inclined to SM in Khartoum state, Sudan. This is expected as they can afford to routinely consult with qualified medical practitioners (Awad et al, 2006). In contrast to our findings, SM was higher in urban areas than in rural areas among Sirlanken people (Pushpa et al, 2012). Opposite results were also reported in the study conducted in urban India (Selvraj et al, 2014); and in a national study on analgesic use in Spain (Carrasco- Garrido et al, 2010).

In addition, In the present study, regarding socioeconomic factors such as age, gender, marital status, work, medical insurance, education, current health status, care about health and drugs stored at home no statistically significantly difference were observed between participants who practiced SM and those who were not except for the residence $\left(\mathrm{F}_{1} ; 10.1, \mathrm{p}=0.002\right.$ and $\mathrm{F}_{2} ; 11.2 \mathrm{p}=$ 0.001), and family expenses $(\mathrm{F} ; 5.51 \mathrm{p}=0.005)$, respectively. Furthermore, our results regarding residence are in accordance with Yasser Awadallah Yasein who revealed that $(71.5 \%)$ were urban residents, while $21.6 \%$ and $7.0 \%$ were rural and Bedouin residents respectively but in contrast to our findings regarding family expenses who showed that there was no statistically 460 
Journal of Environmental Sciences (JES)

Faculty of Graduate Studies and Environmental Research, Ain Shams University

Moussa et al.

significant difference regarding family income, and practice of selfmedication ( $\mathrm{P}>0.05)$, (Yasser Awadallah Yasein et al, 2018).

Possible etiological factors (reasons) for using SM: The most frequent reported cause for SM with drugs in the current study was "no need to visit the doctor for such minor disease" (57.3\%) and the least was "absence in the trust of health services" (22.7\%). While " fear of adverse effects" was the most frequent cause for not SM. This was followed by other reasons in this study such as ''confidence in the pharmacist" (52\%), then 'cost of consultation of the doctor" (50.7\%), after that "'time and money saving', (46.7\%); fast relief (40\%); the doctor will prescribe me the same drug (36.7\%); a chance to gain experience (28\%) and absence of health services $(26 \%)$. Such findings were reported by several studies worldwide (Helal and Abou-ElWafa, 2017; Ghazawy et al, 2017; Farahat et al, 2016; Abay and Amelo, 2010; Sallam et al, 2009; Yousef et al, 2008).

As regard for personal behavior with utilization and effect of selfmedicated drugs in this study, about $44 \%$ of the participants said that selfmedicated drugs solved the symptoms. This is in agreement with (Sallam et $a l, 2009)$, who reported (69.3\%) and (Ghazawy et al, 2017) who reported $(64.2 \%)$ in their respondents used medicine until complaint disappear. In contrast to our results in this study, other findings were reported by (Sharma et al., 2012) where $82 \%$ of their respondents found that self-medicated dugs were ineffective. 
Journal of Environmental Sciences (JES)

Faculty of Graduate Studies and Environmental Research, Ain Shams University

Moussa et al.

Sources of Medications and Information on SM: Our study revealed that easily accessibility of medicines (44.7\%) from private pharmacies without prescription could explain the high percentage of purchasing from these pharmacies as a major source of the practice of SM (WHO, 2000). Also, keeping medicines at home $(80 \%)$ is an important concern led to increase the possibility of SM and mistakes in proper consumption (Khamis et al, 2019).

Regarding the sources of information about the drugs used for SM, the commonest source for information was the pharmacist (72\%) as they can guide consumers and give them the most appropriate OTC medications or consult the doctor if their condition required. This is even more obvious in villages (rural areas), where medical services are less developed (Al-Ramahi, 2013). This was followed by participant's experience or knowledge from previous prescription (39.3\%). This was in agreement with (El-Nimr et al, 2015 and Abdallah, 2014). But in contrast to a study conducted in Singapore, (Chui and Li, 2005); SM upon my own decision of participants (37.3\%) was the third main source of information followed by internet and advertisement (21.3\%); mass media and books and magazines (20.7\%); then family and neighbors (20\%) and the least source was relatives and friends (16.7\%). This was in agreement with those reported by (El-Nimr et al, 2015; Ghazawy et al, 2017). Furthermore, a worldwide review of consumer surveys reported a similar profile of sources of medications and information on SM among the studied populations (Khalifeh et al, 2017). 
In addition, further research is warranted to be generalized so as to extend this study outside the capital city; Cairo to include other cities and slum areas in Egypt. Furthermore, there is a need for an important next step to focus on SM among priority groups such as the elderly, women, children, those with chronic diseases and such studies should be based on a large representative sample size.

\section{CONCLUSION}

This study revealed that the prevalence of SM was $(73.4 \%)$ with medicines is high among adults at different regions (slum and urban) with different socioeconomic status in Cairo, Egypt. Family expenses and residence were major determinants of SM. Our findings suggest that more strict regulations on dispensing of drugs without prescription may be required to reduce health risks related to SM. Targeted public health education program aimed at improving the quality of SM behavior should be considered. Finally, our findings have major public health policy for developing countries like, Egypt.

\section{REFERENCES}

Abay, S. M. and Amelo, W. (2010): Assessment of self-medication practices among medical, pharmacy, and health science students in Gondar University, Ethiopia J Young Pharm, 2(3), 306-310. http://doi.org/https://doi.org/10. 4103/0975-1483.66798.

Abdallah, Q. M. (2014): Medicines use among general public in Taif, KSA. Arch Pharma Pract, 5:125-31.

$$
\begin{aligned}
& \text { Vol. (50); Iss. (11); No. (5); Nov. } 2021 \\
& \text { ISSN 1110-0826 } \\
& \text { ONLINE ISSN } 2636 \text { - } 3178
\end{aligned}
$$


Abdel Aziz, A. I.; Tawfik, A. G.; Rabie, K. A. and Omran, M. et al., (2019): Quality of community pharmacy practice in antibiotic Selfmedication encounters: A simulated patient study in Upper Egypt. Antibiotics, 8, 35.

Al-Ramahi, R. (2013): Patterns and attitudes of self-medication practices and possible role of community pharmacists in Palestine, International Journal of Clinical Pharmacology and Therapeutics, 51 (7), 562567.

Awad, A. I.; Eltayeb, I. B.; Capps, P. A. (2006): Self-medication practices in Khartoum State, Sudan. European Journal of Clinical Pharmacology, 62(4), 317 - 324.

Bennadi, D. (2013): Self-medication: A current challenge. J Basic Clin Pharm, 5(1), 19-23.

Carrasco-Garrido, P.; Hernandez-Barrera, V.; Ana Lopez de Andre's.; Jimenez-Trujillo, I. and Jime'nez-Garc1'a, R.(2010): Sexdifference on self-medication in Spain. Pharmacoepidemiol Drug Saf, 5(1), 32-6.

Chui, W. K.; Li, S.C. (2005): Advice-giving on self-medication: perspectives of community pharmacists and consumers in Singapore. J Clin Pharm Ther, 30, 225-31.

El Ezz, N. and Ez-Elarab, H. (2011): Knowledge, attitude and practice of medical students towards self-medication at Ain Shams University, Egypt. J Prev Med Hyg, 52(4), 196-200.

El-Nimr, N. A.; Wahdan, I. M. H.; Wahdan, A. M. H. and Kotb, R. E. (2015): Self-medication with drugs and complementary and alternative medicines in Alexandria, Egypt: prevalence, patterns and determinants. East Mediterr Health J, 21(4), 256-265. PMID: 26077520 . 
Farahat, T. M.; Shaheen, H. M.; Mohammed, H. M.; et al., (2016): Self-medication among the attendants to a family health center in Al Sadat city, Menoufia Governorate. Menoufia Medical Journal, 29, 1066-1070.

Francis, S. A.; Barnett, N. and Denham, M. (2005): Switching of prescription drug to over the counter status; is it a good thing for the elderly? J Drugs and aging, 22(5), 361-70.

Ghazawy, E. R.; Hassan, E. E.; Mohamed, E. S. and Emam, S. A. (2017): Self-Medication among Adults in Minia, Egypt: A Cross Sectional Community-Based Study. Health, 9(6), 883-95.

Hassali, M. A.; Shafie, A. A.; Al-Qazaz, H.; Tambyappa, J.; Palaian, S. and Hariraj V. (2011): Self-medication practices among adult population attending community pharmacies in Malaysia: an exploratory study, International Journal of Clinical Pharmacy, 33 (5), 794-799.

Helal, R. and Abou-ElWafa, H. (2017): Self-medication in university students from the city of Mansoura, Egypt. J Env Public Health, 2017, 1-6.

How to investigate drug use in health facilities. Selected drug use indicators. Action program on essential drugs. Geneva, World Health Organization, 1993 (WHO/DAP/93.1).

Khalifeh, M. M.; Moore, N. D. and Salameh, P. R. (2017): Self-medication misuse in the Middle East: a systematic literature review. Pharmacology Research \& Perspectives, 5(4), 323.

Khamis, S.; Sheqer, H and Arsoy, G. (2019): Knowledge, Attitude and Practice of Self-medication among Pharmacy Students in North Cyprus. JPRI, 29(4), 1-10. Article no.JPRI.50824.

Lwanga, S. K. and Lemeshow, S. (1991): Sample size determination in health studies: a practical manual. Geneva: World Health Organization. 
Pons, E. d. S.; Knauth, D. R.; Vigo, Â.; PNAUM Research Group.; Mengue, S. S. (2017): Predisposing factors to the practice of selfmedication in Brazil: Results from the National Survey on Access, Use and Promotion of Rational Use of Medicines (PNAUM). PLoS ONE, 12(12), 1-12. e0189098. https://doi.org/10.1371/journal.pone.0189098.

Pushpa, R. W.; Ravindra, L. J. and Rohini de A S. (2012): Prevalence and predictors of self-medication in a selected urban and rural district of Sri Lanka. WHO South-East Asia Journal of Public Health, $1(1), 28-41$.

Sabry, N.; Farid, S. and Dawoud, D. M. (2014): Antibiotic dispensing in Egyptian community pharmacies: An observational study. Research in social and administrative pharmacy, 10(1), 168-184.

Safila, N.; Humera, I.; Bushra, A.; Humera, A.; Mehmeen, M. and Sundus, P. (2014): The prevalence of self-medication in Karachi, World J Pharm Sci. 2(5), 479-484.

Sallam, S.; Khallafallah, N.; Ibrahim, N. and Okasha A. (2009): Pharmacoepidemiological study of self-medication in adults attending pharmacies in Alexandria, Egypt. East Mediterr Health J, 15(3), 683-691.

Selvraj, K.; Ganesh Kumar, S. and Ramalingam, A. (2014): A prevalence of self-medications practices and its associated factors in Urban Puducherry, India. Prespect Clin Res, 5(1), 32-6.

Shankar, P. R.; Partha, P. and Shenoy, N. (2002): Self-medication and nondoctor prescription practices in Pokhara valley, Western Nepal: a questionnaire-based study. BMC Fam Pract, 3, 17.

Sharma, A.; Madaan, A. and Nagappa, A. N. (2012): Medication storage and self-medication practice among the youth in Karnataka region, India. Int J Pharm Sci Res, 3(8), 2795-2800.

SPSS corporation version 12, 2004, Chicago, Illinois, USA. 
Susheela, F.; Goruntla, N.; Bhupalam, P. K.; Veerabhadrappa, K. V.; Sahithi, B. and Ishrar, S. M. G. (2018): Assessment of knowledge, attitude, and practice toward responsible self-medication among students of pharmacy colleges located in Anantapur district, Andhra Pradesh, India. J Educ Health Promot, 7, 96.

Tesfamariam, S.; Anand, I.; Kaleab, G.; Berhane, S.; Woldai, B.; Habte, E. and Russom, M. (2019): Self-medication with over the counter drugs, prevalence of risky practice and its associated factors in pharmacy outlets of Asmara, Eritrea BMC Public Health, 19, 159.

WHO (2000): Guidelines for the regulatory assessment medicinal product for use in self-medications. (Accessed 12 March 2015).

Yasser Awadallah Yasein: Assessment of Self-Medication Practice Among Undergraduate Medical Students In The Eastern Region, Saudi Arabia. IOSR Journal of Nursing and Health Science (IOSRJNHS) , vol. 7, no.1, 2018, pp. 73-82.

Yousef, A. M.; Al-Bakri, A. G.; Bustanji, Y. and Wazaify, M. (2008): Selfmedication patterns in Amman, Jordan. Pharm World Sci, 30, 2430 .

Yuefeng, L.; Keqin, R. and Xiaowei, R. (2012): Use and factors associated with self-treatment in China. BMC Public Health, 12, 995. 


\title{
المسبماهت المرضية المهتملة للمكاواة الذاتية

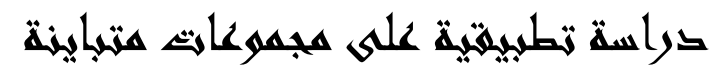

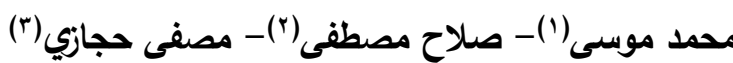

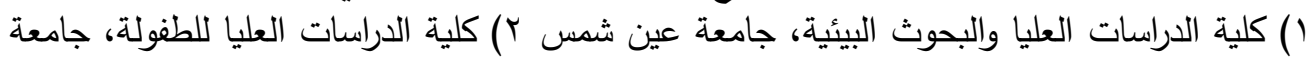

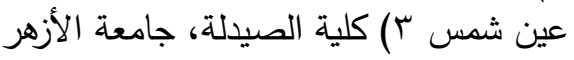

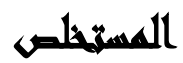

المقدمة: المداواة الذاتية مشكلة صحية متكررة بثكل متزايد في جميع أنحاء العالم خاصة في البلدان

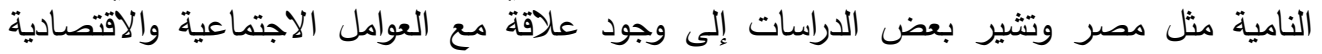
والبيئية.

الههف: هدفت هذه الدراسة إلى وصف الانتثار والنمط والعوامل المسببة المحتملة وأسباب المداواة

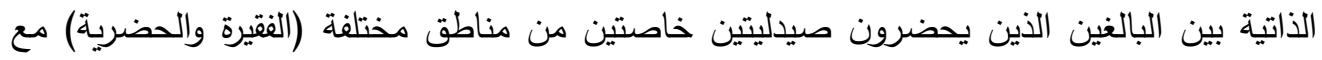

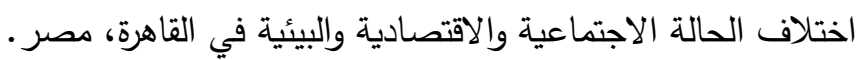

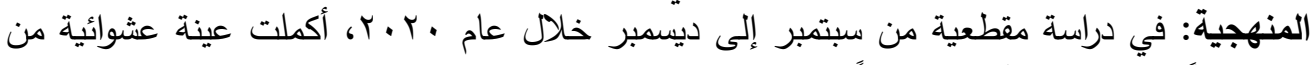

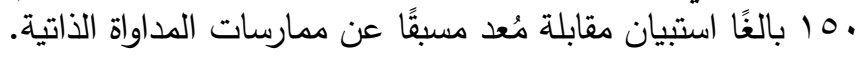

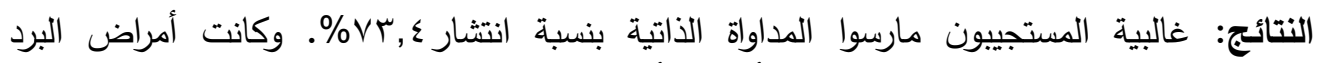

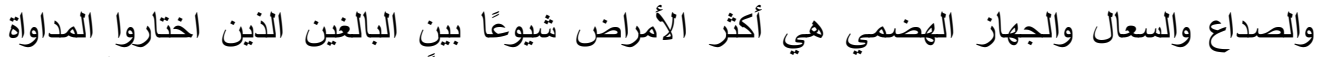

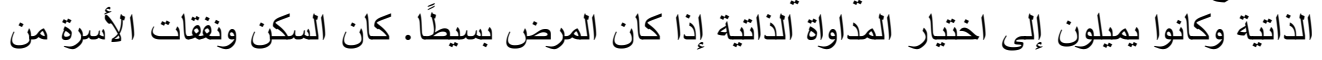

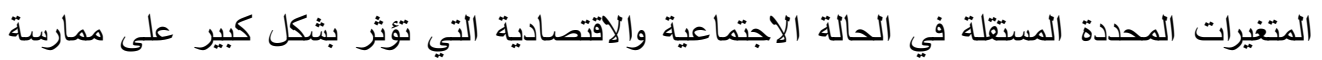

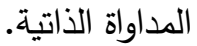
الملخص: النتشار المداواة الذاتية بالعقاقير شاملة الأعشاب مرتفع بين البالغين في المناطق الحضرية

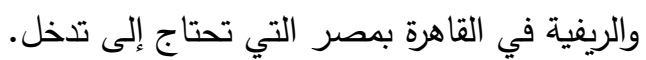

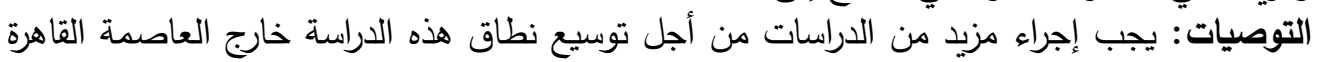

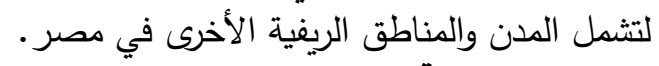

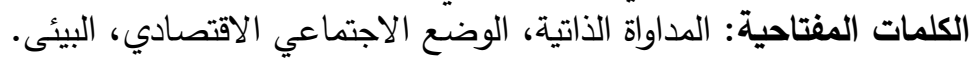

